\title{
The "presyrinx" state: is there a reversible myelopathic condition that may precede syringomyelia?
}

\author{
Nancy J. Fischbein, M.D., William P. Dillon, M.D., Charles Cobbs, M.D.,
} and Philit R. Weinstein, M.D.

Departments of Radiology and Neurosurgery, University of California, San Francisco, California; and Department of Neurosurgery, University of Alabama at Birmingham, Birmingham, Alabama

Object. Alteration of cerebrospinal fluid (CSF) flow has been proposed as an important mechanism leading to the development of syringomyelia. We hypothesize that a "presyrinx" condition due to potentially reversible alteration in normal CSF flow exists and that its appearance may be due to variations in the competence of the central canal of the spinal cord.

Methods. Five patients with clinical evidence of myelopathy, no history of spinal cord trauma, enlargement of the cervical spinal cord with $\mathrm{T}_{1}$ and $\mathrm{T}_{2}$ prolongation but no cavitation, evidence for altered or obstructed CSF flow, and no evidence of intramedullary tumor or a spinal vascular event underwent MR imaging before and after intervention that alleviated obstruction to CSF flow.

Results. Preoperatively, all patients demonstrated enlarged spinal cords and parenchymal $\mathrm{T}_{1}$ and $\mathrm{T}_{2}$ prolongation
alleviated obstruction to $\mathrm{CSF}$ flow. without cavitation. Results of magnetic resonance (MR) imaging examinations following intervention in all patients showed resolution of cord enlargement and normalization or improvement of cord signal abnormalities. In one patient with severe arachnoid adhesions who initially improved following decompression, late evolution into syringomyelia occurred in association with continued CSF obstruction.

Conclusion. Nontraumatic obstruction of the CSF pathways in the spine may result in spinal cord parenchymal $\mathrm{T}_{2}$ prolongation that is reversible following restoration of patency of CSF pathways. We refer to this MR appearance as the "presyrinx" state and stress the importance of timely intervention to limit progression to syringomyelia.

KEY Words • spine • cervical • syrinx • magnetic resonance imaging

Syringomyelia occurs in a number of clinical settings, most commonly following trauma ${ }^{32,37,44}$ or in association with a Chiari malformation..$^{2,10,22,46}$ Other causes include infectious or inflammatory arachnoiditis, ${ }^{3,4,17,22,31}$ tumors of the spine and spinal cord, ${ }^{22}$ posterior fossa tumors, ${ }^{18}$ and cervical spondylosis. ${ }^{16}$ Syringes typically appear as well-defined discrete cavities containing fluid that is isointense to CSF on all sequences. ${ }^{1,13}$ The pathophysiology of syringomyelia is controversial, but experimental models $s^{5,27,47}$ and clinical studies ${ }^{12,29}$ have implicated alterations in CSF flow as a significant factor in the development and progression of certain types of syringomyelia. The hypothesis that CSF normally flows along perivascular spaces within the parenchyma of the spinal cord to the central canal is supported by experimental studies. ${ }^{6,21,35}$ $36,39-41$ Variations in patency of the central canal of the spinal cord have been associated with the development of

Abbreviations used in this paper: $\mathrm{CSF}=$ cerebrospinal fluid; $\mathrm{CT}=$ computerized tomography $\mathrm{MR}=$ magnetic resonance PPMM = posttraumatic myelomalacic myelopathy. different types of syringomyelia ${ }^{26,27}$ and likely play a role in determining the location of a syrinx remote from a focus of CSF obstruction as is commonly seen in the Chiari I malformation. The reversibility of syringomyelia following restoration of CSF pathways has been well documented in patients undergoing posterior fossa decompression for Chiari malformation, removal of extradural masses, and lysis of adhesions. ${ }^{17,18,24}$

We identified five myelopathic patients with no history of spine trauma who had underlying conditions associated with alterations of CSF flow. These patients had enlargement and $\mathrm{T}_{2}$ prolongation of the spinal cord, without frank cavitation, on MR imaging studies which improved or reversed following restoration of CSF flow pathways. We hypothesized on the basis of historical, imaging, and operative findings that obstruction to normal CSF flow pathways resulted in the cord enlargement and MR signal abnormalities that reversed following restoration of normal CSF pathways. We also hypothesized that variation in patency of the central canal of the spinal cord plays a role in the genesis of this "presyrinx" state. 
TABLE 1

Summary of Patient Dato

\begin{tabular}{|c|c|c|c|c|c|}
\hline $\begin{array}{l}\text { Patient } \\
\text { No. }\end{array}$ & $\begin{array}{c}\text { Figure } \\
\text { No. }\end{array}$ & $\begin{array}{l}\text { Age (yrs), } \\
\text { Sex }\end{array}$ & History & $\begin{array}{c}\text { Clinical } \\
\text { Condition Preop } \\
\end{array}$ & Previous Surgery \\
\hline 1 & 1 & $2, \mathrm{M}$ & Chiari I malformation & $\begin{array}{l}\text { severe headaches, progressive } \\
\text { clumsiness in limb move- } \\
\text { ments over the course of } 1 \mathrm{yr}\end{array}$ & $\begin{array}{l}\text { limited decompression (suboc- } \\
\text { cipital craniectomy) for } \\
\text { Chiari I malformation }\end{array}$ \\
\hline 2 & 2 & $69, \mathrm{~F}$ & $\begin{array}{l}\text { polymyalgia rheumatica, pre- } \\
\text { vious epidural abscess associated } \\
\text { with osteomyelitis of the cervi- } \\
\text { cal spine }\end{array}$ & $\begin{array}{l}\text { progressive quadriparesis, pro- } \\
\text { gressive loss of sensation } \\
\& \text { motor control in hands }\end{array}$ & $\begin{array}{l}\text { decompression of epidural abscess } \\
\text { via C-6 laminectomy } 18 \text { mos } \\
\text { earlier }\end{array}$ \\
\hline 3 & 4 & $41, \mathrm{M}$ & $\begin{array}{l}\text { remote history of head trauma; } \\
\text { basilar arachnoid adhesions; } \\
\text { history of hydrocephalus }\end{array}$ & $\begin{array}{l}\text { progressive neck pain and } \\
\text { spastic quadriparesis }\end{array}$ & $\begin{array}{l}\text { posterior fossa decompression } \\
\text { VP shunt for hydrocephalus }\end{array}$ \\
\hline 4 & 3 & $40, \mathrm{~F}$ & $\begin{array}{l}\text { Grade III SAH caused by aneurysm } \\
\text { status post GDC coil embolization; } \\
\text { course complicated by S. epidermis } \\
\text { meningitis }\end{array}$ & neck pain and quadriparesis & $\begin{array}{l}\text { coil embolization of aneurysm, } \\
\text { external ventricular drainage } \\
\text { of CSF }\end{array}$ \\
\hline 5 & NS & $77, \mathrm{~F}$ & $\begin{array}{l}\text { severe cervical spondylostenosis } \\
\& \text { mild basilar impression }\end{array}$ & $\begin{array}{l}\text { progressive weakness in both } \\
\text { arms, right greater than left, } \\
\& \text { hand numbness; spasticity } \\
\text { \& incoordination of legs; } \\
\text { no neck pain }\end{array}$ & none \\
\hline
\end{tabular}

$* \mathrm{FM}=$ foramen magnum; $\mathrm{SAH}=$ subarachnoid hemorrhage $; \mathrm{GDC}=$ Guglielmi detachable coils; $\mathrm{NS}=$ not shown $; \mathrm{VP}=$ ventriculoperitoneal; S. epider midis $=$ Staphylococcus epidermidis.

\section{METHODS}

Over a 2-year period, five patients who met the following criteria were identified prospectively: clinical evidence of myelopathy, no history of spinal cord trauma, enlargement of the cervical cord with parenchymal $\mathrm{T}$, and $\mathrm{T}$ prolongation but no frank cavitation, and no evidence of intramedullary tumor or a spinal vascular event as the cause of cord signal changes. No patient had evidence of active inflammatory or demyelinating disease or received steroid therapy. In addition, all patients had obstruction to CSF flow at the level of the foramen magnum or the spinal epidural or subarachnoid space based on historical and/or imaging features. Our patients included two males and three females and ranged in age from 2 to 77 years. Clinical records and imaging studies for these patients were reviewed.

All patients underwent preoperative imaging on a $1.5 \mathrm{~T}$ MR system. Imaging sequences included conventional spin-echo $\mathrm{T}$-weighted images (500/14 [TR/TE], $4 \mathrm{~mm}$ thick, $256 \times 256$ matrix $)$ and fast spin-echo $\mathrm{T}_{2}$-weighted images (3000/105eff, [TR/TE], echotrain length $8,3 \mathrm{~mm}$ thick, $256 \times 256$ matrix) obtained in the sagittal plane in addition to axial $\mathrm{T}_{1}$-weighted images. A proton densityweighted sequence was not obtained since it is not part of our routine spine imaging protocol. Contrast-enhanced images were obtained in three patients and included sagittal and axial $\mathrm{T}_{1}$-weighted sequences. Magnetic resonance examinations were conducted on all patients after surgical intervention and included, at a minimum, sagittal $\mathrm{T}_{1}$ and fast spin-echo $\mathrm{T}_{2}$-weighted sequences. In addition, one patient underwent CT myelography preoperatively, and one patient underwent CT myelography postoperatively. Only one patient had an MR flow study performed preoperatively, utilizing a cine phase contrast technique (24/minimum, [TR/TE], flip angle $30^{\circ}, 256 \times 128$ matrix, flow compensation and peripheral gating applied, velocity encoding gradient $=5 \mathrm{~cm} / \mathrm{second}$ to evaluate CSF flow at the foramen magnum.

\section{RESULTS}

A summary of our patients' histories, as well as clinical and imaging findings, is presented in Table 1 . All patients underwent MR imaging of the cervical spinal cord to evaluate myelopathic symptoms, although in one case (Case 1) headaches were the dominant clinical feature. The clinical presentations were similar to that of patients with central cystic myelopathy, ${ }^{22,} 23$ including increasing loss of motor function or weakness in all patients, sensory changes in two patients, increased spasticity in two patients, and radicular pain in one patient. The conditions that predisposed our patients to alterations in CSF flow dynamics and myelopathy included the following: Chiari I malformation with severe tonsillar herniation; prior osteomyelitis complicated by epidural abscess, meningitis and arachnoiditis; basilar arachnoid adhesions related to prior head trauma, traumatic subarachnoid hemorrhage, and posterior fossa surgery; subarachnoid hemorrhage complicated by meningitis leading to severe hydrocephalus and tonsillar herniation; and rheumatoid arthritis with severe cervical spondylosis and spinal stenosis accompanied by basilar impression. In all five cases, the lesion occurred in the cervical spinal cord.

Results of preoperative MR imaging demonstrated a variable degree of enlargement of the cervical cord in all patients. All patients had abnormal $\mathrm{T}_{1}$ and $\mathrm{T}_{2}$ prolongation of the cervical spinal cord signal extending over a variable distance. The $\mathrm{T}_{1}$ signal was not as low as CSF in any case, and the margins of the $T_{1}$ signal abnormality were not sharply defined. No frank cavitation was observed in any 
TABLE 1, CONTINUED

Summary of Patient Data

\begin{tabular}{|c|c|c|c|}
\hline MR Findings Preop & Surgical Intervention & $\begin{array}{l}\text { Clinical Findings } \\
\text { Postop }\end{array}$ & MR Findings Postop \\
\hline $\begin{array}{l}\text { progressive } \mathrm{T}_{1} \text { and } \mathrm{T}_{2} \text { prolonga- } \\
\text { tion within upper cervical cord; } \\
\text { no cavity; tonsillar herniation } \\
\text { w/ reduced CSF flow at FM }\end{array}$ & $\begin{array}{l}\text { aggressive suboccipital decompres- } \\
\text { sion and partial resection of cere- } \\
\text { bellar tonsils }\end{array}$ & $\begin{array}{l}\text { improved headaches, de- } \\
\text { creased clumsiness }\end{array}$ & $\begin{array}{l}\text { near-resolution of } \mathrm{T}_{1} \text { and } \mathrm{T}_{2} \text { pro- } \\
\text { longation in cord substance; im- } \\
\text { proved CSF flow at foramen } \\
\text { magnum }\end{array}$ \\
\hline $\begin{array}{l}\text { marked enlargement of midcervical } \\
\text { cord; } \mathrm{T}_{1} \text { and } \mathrm{T}_{2} \text { prolongation } \\
\text { from } \mathrm{C} 3-4 \text { to } \mathrm{T} 1-2 \text {; large ventro- } \\
\text { lateral osteophyte at } \mathrm{C} 3-4 \text { level }\end{array}$ & $\begin{array}{l}\text { C3-7 laminectomy, lysis of sub- } \\
\text { dural adhesions, and sectioning } \\
\text { of dentate ligaments at C3 and C4 }\end{array}$ & $\begin{array}{l}\text { substantial improvement in } \\
\text { strength, sensation in arms } \\
\& \text { legs w/in hours postop }\end{array}$ & $\begin{array}{l}\text { decrease in cord caliber; persistent } \\
\mathrm{T}_{1} \text { and } \mathrm{T}_{2} \text { prolongation below } \\
\mathrm{C} 3-4 \text { level, where the cord re- } \\
\text { mains focally adhesed }\end{array}$ \\
\hline $\begin{array}{l}\text { cord enlargement from } \mathrm{C} 1 \text { to } \mathrm{T} 3 \\
\mathrm{w} / \mathrm{T}_{1} \text { and } \mathrm{T}_{2} \text { prolongation }\end{array}$ & $\begin{array}{l}\text { C6-7 laminectomy w/ exploration } \\
\text { \& myelotomy, but no shunt as a } \\
\text { syrinx cavity was not found }\end{array}$ & $\begin{array}{l}\text { slight improvement in right } \\
\text { hand function; decreased } \\
\text { neck \& arm pain }\end{array}$ & $\begin{array}{l}\text { progressive decrease in cord en- } \\
\text { largement } \& \mathrm{~T}_{1} \text { and } \mathrm{T}_{2} \text { prolonga- } \\
\text { tion; then late decline \& progres- } \\
\text { sion to frank syrinx formation }\end{array}$ \\
\hline $\begin{array}{l}\text { cervical cord enlargement } \mathrm{w} / \mathrm{T}_{1} \\
\& \mathrm{~T}_{2} \text { prolongation; enlarged } \\
\text { ventricles w/ tonsillar her- } \\
\text { niation }\end{array}$ & $\begin{array}{l}\text { VP1 shunting to relieve hydro- } \\
\text { cephalus }\end{array}$ & $\begin{array}{l}\text { improved mental status, de- } \\
\text { creased neck stiffness, res- } \\
\text { olution of quadriparesis }\end{array}$ & $\begin{array}{l}\text { complete resolution of cord en- } \\
\text { largement \& signal abnormalities }\end{array}$ \\
\hline $\begin{array}{l}\text { severe cervical spondylostenosis, } \\
\text { basilar impression, \& atlanto- } \\
\text { axial subluxation; cord enlarge- } \\
\text { ment \& edema from cervico- } \\
\text { medullary junction to C6-7 }\end{array}$ & $\begin{array}{l}\text { C1-6 laminectomies w/ medial } \\
\text { facetectomies, then posterior } \\
\text { fusion from C-4 to C- } 6\end{array}$ & $\begin{array}{l}\text { stabilization of neurological } \\
\text { findings; mild improvement } \\
\text { in lower extremity spasticity }\end{array}$ & $\begin{array}{l}\text { decreased cord enlargement \& sig- } \\
\text { nificant decrease in cord signal } \\
\text { abnormality }\end{array}$ \\
\hline
\end{tabular}

patient. Mild parenchymal enhancement of the upper cervical cord was observed in one case; this patient had no evidence of an acute clinical decline or systemic infectious or inflammatory condition, and her CSF profile was benign.

Evidence of a discrete level of obstruction to normal CSF flow could be identified pre-operatively in all but one patient. The patient in Case 1 (Fig. 1) had a Chiari I malformation with markedly narrowed CSF spaces at the level of the foramen magnum; a cine phase-contrast CSF flow study showed markedly restricted flow of CSF through the foramen magnum. The patient in Case 2 (Fig. 2) underwent preoperative CT myelography that showed a decreased flow of contrast around a swollen cervical spinal cord and a myelographic block at the C3-4 leve caused by a large ventrolateral osteophyte and possibly adhesions as well; subtle increased density of the cord on delayed images was also found. The patient in Case 4 (Fig. 3) harbored a markedly enlarged fourth ventricle and tonsillar herniation which resulted in obstruction to flow at the level of the foramen magnum. The patient in Case 5 had multilevel spondylostenosis and marked compression at the level of the foramen magnum due to basilar impression and atlantoaxial subluxation. In all these cases, the level of obstruction was rostral to the level of cord signal changes. The level of obstruction in Case 3 was not clear preoperatively; this patient had a history of prior posterior fossa surgery and basilar adhesions that were most likely causing obstruction to flow at the level of the foramen magnum, but he also had a mild congenital spinal stenosis with superimposed acquired stenosis at C5-6 and C6-7. In this case, it is unclear whether the spinal cord signal changes were only caudal or both rostral and caudal to the level of obstruction to CSF flow.

Four of five patients underwent operative intervention directed at restoring patency of CSF pathways. The patient in Case 3 (Fig. 4) underwent laminectomy and intradural exploration for placement of a syringopleural shunt, but this procedure was aborted because no syrinx was found (vide infra). Procedures performed are summarized in Table 1. Only the patient in Case 3 underwent intraoperative ultrasound evaluation of the spinal cord. Postoperatively, all patients experienced clinical improvement to varying degrees.

Postoperative MR imaging was performed in all patients from 1 week to 1 year after surgery. In all cases the postoperative images showed a reduction in cord caliber, as well as improvement or resolution of $\mathrm{T}_{1}$ and $\mathrm{T}_{2}$ signal abnormalities. One patient (Case 3, Fig. 4) experienced a subsequent deterioration in his clinical status after having demonstrated some improvement in clinical and imaging findings in the immediate post-operative period after lower cervical laminectomy and myelotomy. A second postoperative scan six weeks after surgery showed an increase in central parenchymal $\mathrm{T}_{2}$ prolongation. No definite evidence was found for recurrent CSF obstruction at the surgical level, but the cord remained deformed at the level of the foramen magnum, and it was considered likely that obstruction to normal CSF flow remained at the foramen magnum level that had not been addressed surgically; a cine phase-contrast CSF flow study was not performed at this time, because this sequence was unavailable at the rehabilitation hospital where the patient was imaged. No further intervention was undertaken after that study for psychosocial reasons, and the patient was examined by his neurosurgeon 10 months later because of symptom progression. A third postoperative study at this time revealed progression to frank syrinx formation. At this time a syringopleural shunt was placed, but the patient experienced only minimal symptomatic improvement.

\section{DISCUSSION}

The understanding of the pathogenesis of syringomye- 


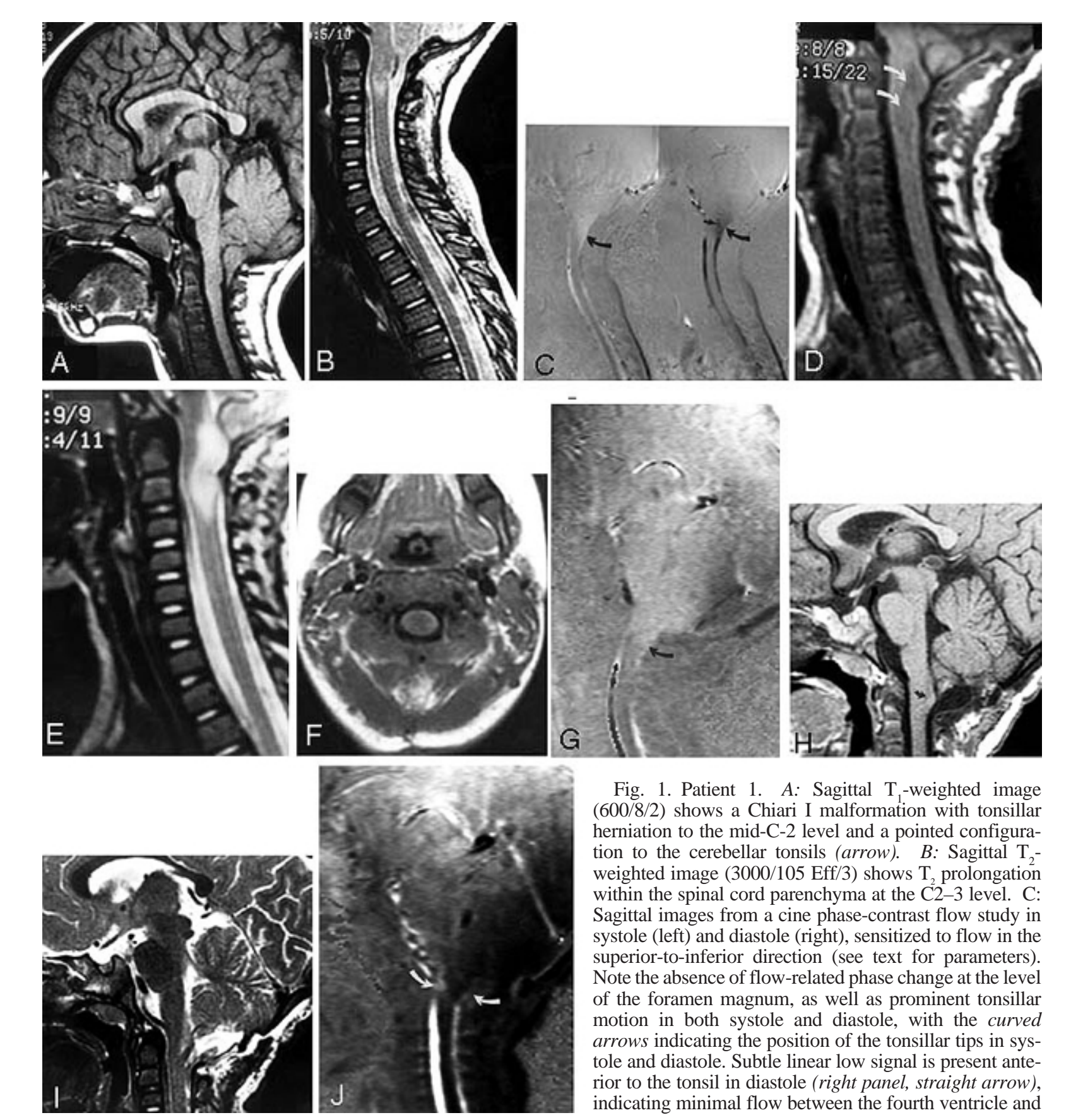

the spinal subarachnoid space below the level of the foramen magnum. D: Sagittal $\mathrm{T}_{1}$-weighted image (500/14/3) obtained 6 weeks later after limited extradural decompression of the foramen magnum. Cord expansion and parenchymal hypointensity (curved arrows) are present in the upper cervical cord. E: Sagittal $\mathrm{T}_{2}$-weighted image (3000/105 Eff/3) corresponding to D shows marked upper cervical cord $\mathrm{T}_{2}$ prolongation. This was presumed related to ongoing or increased obstruction to CSF flow. F: Axial T -weighted image (500/13/2) shows that the central parenchymal signal abnormality is somewhat ill-defined and not as low in signal intensity as CSF. G: Cine phase-contrast flow study sensitized to motion in the superior-to-inferior direction (see text for parameters) shows prominent downward motion of the brainstem and cerebellar tonsils (which appear white), but no definite flow of CSF at the foramen magnum. The tip of the tonsil is indicated (curved arrow). H: Sagittal $\mathrm{T}_{1}$-weighted image (600/8/2) following aggressive decompression of the foramen magnum, including duraplasty, lysis of arachnoid adhesions, and partial tonsillar resection shows the upper cervical cord appears normal caliber. Minimal parenchymal hypointensity persists in the upper cervical spinal cord (curved arrow). I: Sagittal $\mathrm{T}_{2}$-weighted image (4000/105 Eff/2) corresponding to $\mathrm{H}$ shows near-complete resolution of previously seen abnormal $\mathrm{T}$, prolongation. J: Cine phase-contrast flow study sensitized to motion in the superior-to-inferior direction (see text for parameters) no longer shows abnormal downward motion of the brainstem or residual cerebellar tonsils. CSF flow is evident at the foramen magnum (curved arrows). 


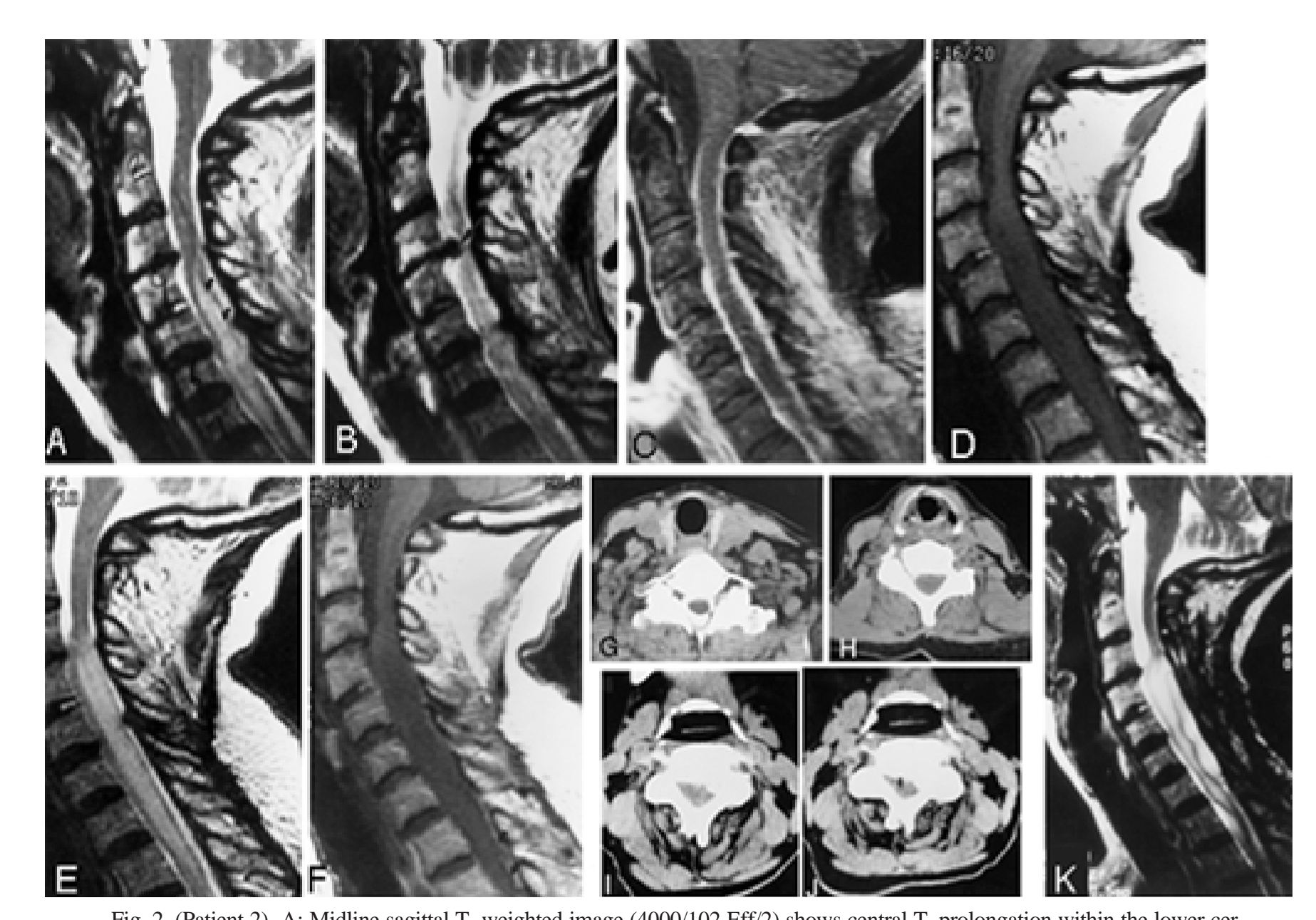

Fig. 2. (Patient 2) A: Midline sagittal $\mathrm{T}_{\mathrm{T}}$-weighted image (4000/102 Eff/2) shows central $\mathrm{T}_{2}$ prolongation within the lower cervical spinal cord parenchyma (arrows). B: Parasagittal T -weighted image (4000/102 Eff/2) shows a large paracentral disc/osteophyte complex at the C3-4 level (arrow). C: Contrast-enhanced sagittal T -weighted image (650/15/2) with fat saturation shows intense meningeal enhancement along the surface of the spinal cord. The patient was treated aggressively with broad-spectrum intense meningeal enhancement along the surface of the spinal cord. The patient was treated aggressively with broad-spectrum
antibiotics and a decompressive laminectomy at C6 for a parasagittal epidural abscess (not shown). D: Sagittal T, ${ }_{1}$-weighted image (600/11/3) obtained 16 months later shows marked enlargement of the cervical spinal cord below the C3-4 level. The parenchyma is hyperintense compared with CSF, and no there is no evidence for frank cavitation. E: Sagittal $\mathrm{T}_{2}$-weighted image (4000/102/2) confirms the marked enlargement of the cervical cord below the $\mathrm{C}_{3}-4$ level, as well as extensive and confluent $\mathrm{T}_{2}$ prolongation within the central cord parenchyma. The cord surface is slightly irregular at C3-4, suggesting possible adhesions. F: Contrast-enhanced sagittal T-weighted image (650/11/2) shows no abnormal enhancement of the cord parenchyma. Faint linear increased signal dorsal to the cord (arrows) likely represents residual thickening and fibrosis of the dura/epidural space related to the prior intense inflammatory episode. G: Cervical CT myelogram was obtained several days later, via a lumbar approach. An axial image at the C7-T1 level shows normal-appearing spinal cord surrounded by dense intrathecal contrast. H: Axial image from the CT myelogram at the C5-6 level shows marked cord enlargement and minimal intrathecal contrast along the right lateral cord. I: Axial image gram at the C5-6 level shows marked cord enlargement and minimal intrathecal contrast along the right lateral cord. I: Axial image
from the CT myelogram at the C3-4 level shows a narrow spinal canal, a left lateral calcified disc/osteophyte complex, and a lack of contrast around the spinal cord. J: Delayed CT image obtained 6 hours after the initial study shows subtle increased density of the peripheral parenchyma at the C3-4 level consistent with penetration of contrast medium. The central cord (arrow) stands out in subtle contrast to the more dense peripheral white matter. K: Postoperative sagittal $\mathrm{T}_{2}$-weighted image (4000/102 Eff/2) obtained after C3-7 laminectomy, lysis of subdural adhesions, and sectioning of the dentate ligaments at C-3 and C-4 show a marked decrease in cord caliber. Parenchymal $\mathrm{T}_{2}$ prolongation persists, as does irregularity consistent with persistent adhesions/obstruction at the C3-4 level. Because the patient was symptomatically improved, it was elected to follow her with serial imaging studies rather than to reoperate.

lia has been significantly advanced by the studies of Milhorat, et al. ${ }^{22-24}$ On the basis of detailed histopathological findings, they distinguish among three types of spinal cord cavities: 1) dilations of the central canal that communicate directly with the fourth ventricle (communicating syringes); 2) noncommunicating dilations of the central canal that arise below a syrinx-free segment of spinal cord; and

Neurosurg. Focus / Volume 8 / March, 2000
3) extracanalicular syringes that originate in the spinal cord parenchyma and do not communicate with the central canal. By correlating with clinical parameters, they were able to associate these distinct cavitary patterns with different mechanisms of pathogenesis. Communicating syringes were found in association with hydrocephalus and were caused by obstruction of CSF circulation distal 


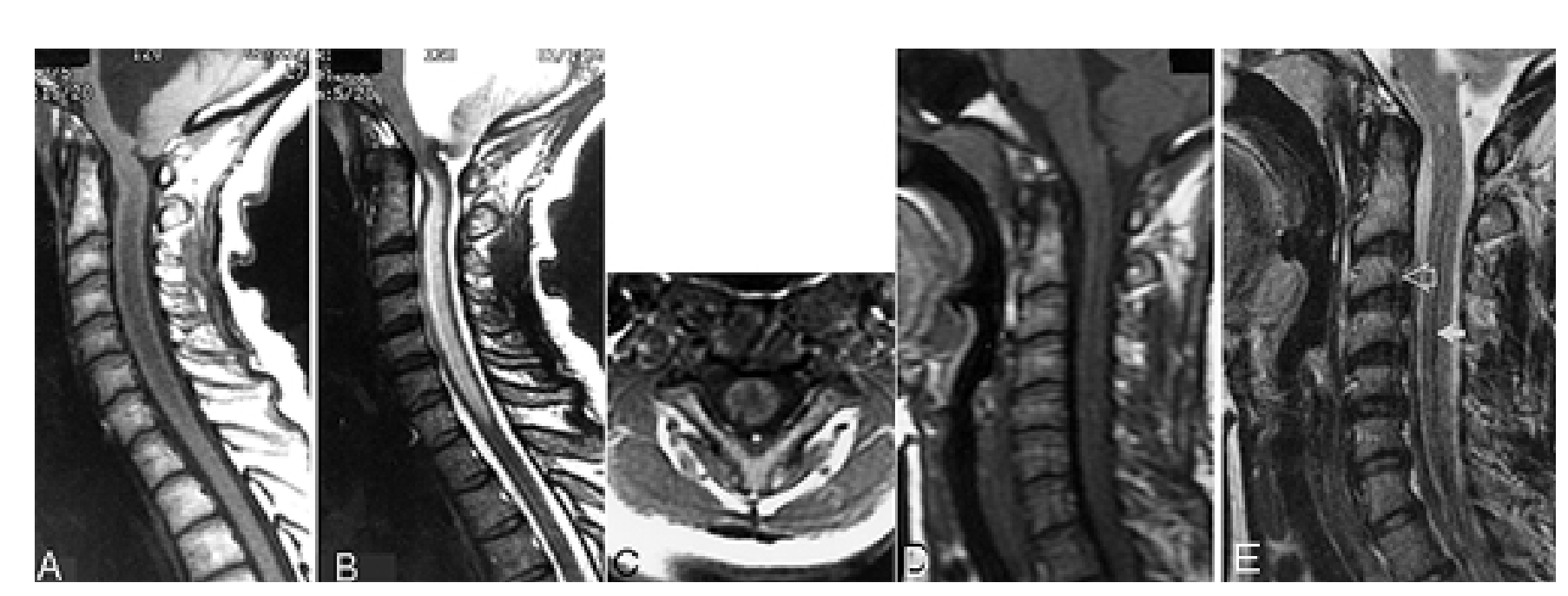

Fig. 3. (Patient 4) A: Sagittal T1-weighted image (500/15/2) shows enlargement of the cervical cord and central parenchymal hypointensity. There is marked enlargement of the fourth ventricle and secondary tonsillar herniation with crowding of the foramen magnum. B: Sagittal T2-weighted image (2500/102 Eff/2) demonstrate striking T-2 prolongation within the central portion of the cord. C: Axial T1-weighted image (583/17/2) at the C2-3 level shows that the central cord hypointensity has an irregular margin and is not isointense to CSF. D: Sagittal T1-weighted image (500/14/1.5) following treatment of hydrocephalus. The fourth ventricle is decompressed, the cerebellar tonsils are normally positioned, and cord caliber has returned to normal. E: Sagittal T2-weighted image (2500/102 Eff/2) shows complete resolution of previously noted parenchymal T-2 prolongation. A dark line down the center of the cord (solid arrow) is presumably artifactual because patient motion and/or truncation artifact, as other parallel lines (open arrow) are observed across the image.

to the outlets of the fourth ventricle. Noncommunicating syringes were associated with disorders of CSF dynamics in the spinal subarachnoid space, such as the Chiari I malformation, cervical spinal stenosis, basilar impression, and arachnoiditis. Extracanalicular or parenchymal syringes were typically found in the watershed area of the spinal cord, associated with conditions that cause direct injury to spinal cord tissue such as trauma, infarction, and hemorrhage. Additionally, they found that concentrically enlarged central cavities (as are seen with communicating or noncommunicating syringes) either were asymptomatic or were associated with bilateral, nonspecific neurological findings, such as spasticity, weakness, and segmental pain.

The theory that noncommunicating syringomyelia is related to alterations in CSF flow has received experimental support. Several groups of investigators $\mathrm{s}^{6,35,36,40,41}$ have shown in animal models that, under normal circumstances, CSF flows from the spinal subarachnoid space into perivascular spaces of the spinal cord and from there along the interstitial spaces toward the central canal. This net unidirectional flow is hypothesized to be driven by both pulsatile and bulk mechanisms, ${ }^{21}$ although it is unclear whether the impetus to flow is actual arterial pulsations within the spinal cord or the transmission of intracranial arterial pulsations to the CSF in the spinal subarachnoid space. Both accentuation of arterial pulsations during systole as well as redirection and accentuation of CSF pulsations transmitted through the subarachnoid space are theorized to account at least in part for the formation and expansion of cysts in noncommunicating types of syringomyelia, although additional experimental work is necessary to investigate these hypotheses. The role of adhesive arachnoiditis in syrinx formation has also been investigated experimentally. ${ }^{17}$ Subarachnoid block caused by adhesive arachnoiditis may initiate the formation or enlargement of a syringomyelic cavity, perhaps by redirecting and/or accentuating transmission of the force of systolic arterial pulsations.

The development of noncommunicating syringomyelia, or focal central canal dilation remote form the site of CSF obstruction may relate to variations in the patency of the central canal among individuals. Milhorat, et al., ${ }^{22}$ showed that noncommunicating syringes were defined rostrally as well as caudally by stenosis of the central canal. An autopsy study of 232 patients without spinal cord pathology by this same group ${ }^{25}$ indicated that stenosis of the central canal correlates with the age of the patient. Varying degrees of stenosis were present at one or more levels in $3 \%$ of infants under 1 year of age, $88 \%$ of adolescents and young adults (aged 13 to 29 years), and $100 \%$ of those over age 65 . They concluded that the incidence and extent of central canal stenosis in humans almost certainly affects the clinical features of syringomyelia. Theoretically, a disturbance of CSF circulation in the spinal subarachnoid space forces redirects fluid through the interstitial spaces of the spinal cord and eventually into a patent segment of the central canal. Focal obliteration of the central canal above this level prevents communication between the syrinx and the fourth ventricle, initiating the conditions required for establishment of noncommunicating syringomyelia.

Clinical studies also support the importance of CSF flow patterns and subarachnoid space pressure waves in the initiation and propagation of syringomyelia. Oldfield, et al., ${ }^{12,29}$ studied seven patients with Chiari I malformation and syringomyelia by using MR imaging and intraoperative ultrasound. On the basis of their observations, they suggest that the development and progression of noncommunicating syringes associated with the Chiari I mal- 


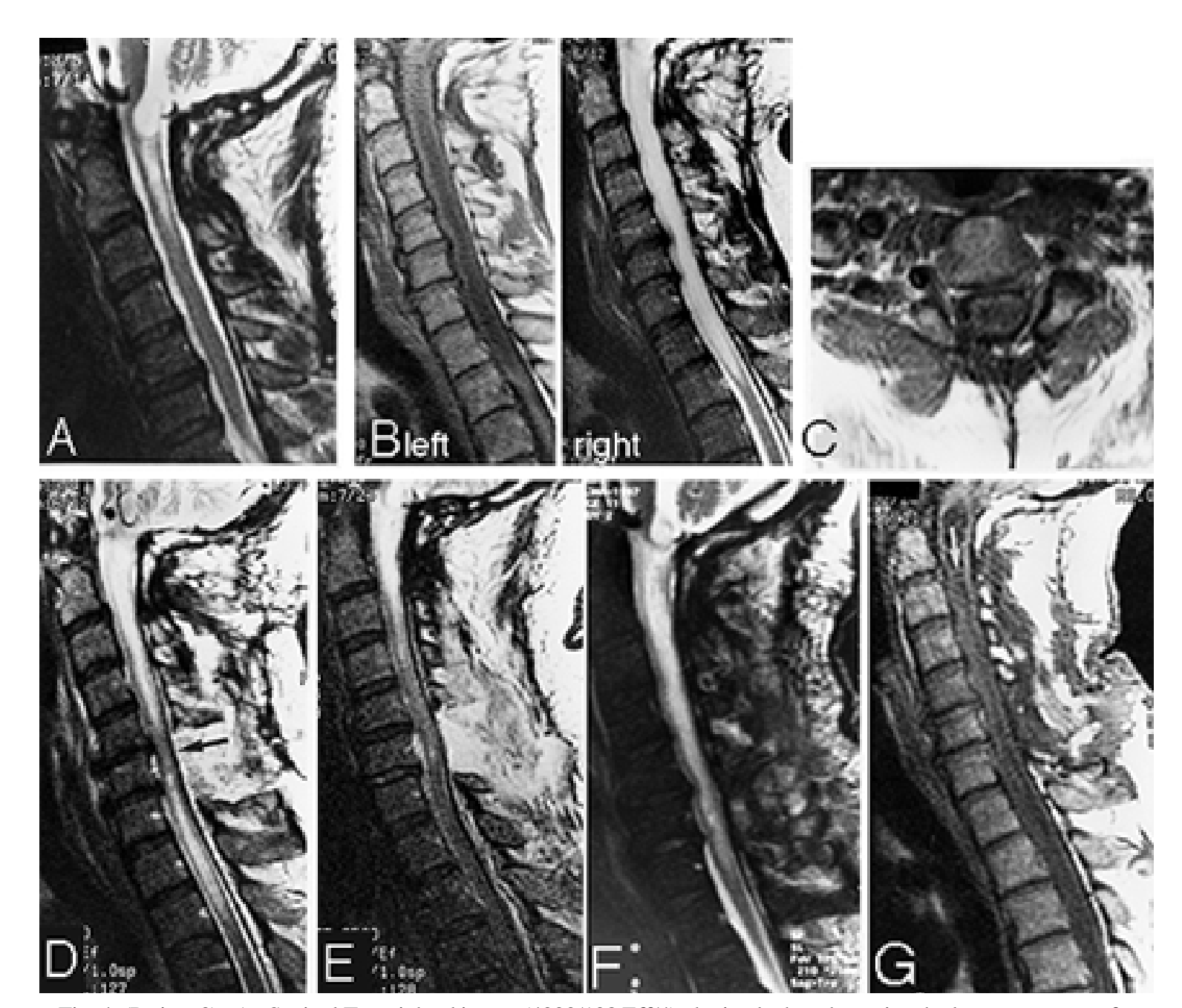

Fig. 4. (Patient 3) A: Sagittal T-weighted image (4000/108 Eff/4) obtained when the patient had no symptoms referable to the spinal cord shows a mild dilation of the obex/proximal central canal and central $\mathrm{T}_{2}$ prolongation within the Eff/2) images obtained 1 year later when the patient had developed progressive neck pain and spastic quadriparesis show striking cord expansion and both $\mathrm{T}_{1}$ and $\mathrm{T}_{2}$ prolongation within the cervical spinal cord. The areas of abnormal signal within the cord approach but are not quite equal to CSF in intensity. C: Axial T, -weighted image (650/9/3) shows irregularly marginated central parenchymal hypointensity, although this area is hyperintense compared with CSF in the spinal canal. These images $(A-C)$ were interpreted as consistent with syrinx by the neurosurgeon, and the patient was taken to the operating room for shunt placement. Intraoperatively, the cord was noted to be enlarged and "boggy." A myelotomy was made at the C-6 level, and a small amount of fluid exuded from the cord surface, but no syrinx was encountered. Intraoperative ultrasound (not shown) confirmed the lack of frank cavitation. D: Sagittal $\mathrm{T}_{2}$-weighted image (3500/96 Eff/3) obtained two days postoperatively shows evidence of recent C6-7 laminectomy. The cord is notably reduced in overall caliber compared with the pre-operative study, and the signal has normalized at the myelotomy site (arrow). E: Repeat $\mathrm{T}$-weighted image (2500/105 Eff/3) obtained 8 days later shows further regression of signal abnormality and further reduction of cord caliber. F: Sagittal T-weighted image (3894/112 Eff/1) obtained 1 month later shows an increase in central $\mathrm{T}_{2}$ prolongation within the cervical spinal cord, as well as an increase in cord caliber. The patient was doing fairly well in rehabilitation and did not desire further intervention. The patient was lost to follow up for 10 months. G: Sagittal $\mathrm{T}_{1}$-weighted image (500/8/3) obtained 11 months following surgery demonstrate further enlargement of the cervical and upper thoracic spinal cord. The cord centrally is hypointense, and multiple septations are present (arrow), consistent with syringomyelia. The patient clinically was severely quadriparetic and had lost control of bowel and bladder function. After this image, surgery was performed, during which a large syrinx was encountered and a syringopleural shunt was placed (not shown).

formation are due to obstruction to the normal rapid toand-fro movement of CSF across the foramen magnum by tonsillar ectopia and the ventral position of the lower brainstem. During systole in the Chiari I malformation, brain expansion is accommodated by abrupt caudal move- ment of the tonsils. This downward, pistonlike systolic tonsillar movement can be shown on direction-sensitive cine phase contrast MR sequences (Fig. 1C). Rapid downward tonsillar movement, perhaps in concert with the deposition of fourth ventricular CSF into the spinal sub- 


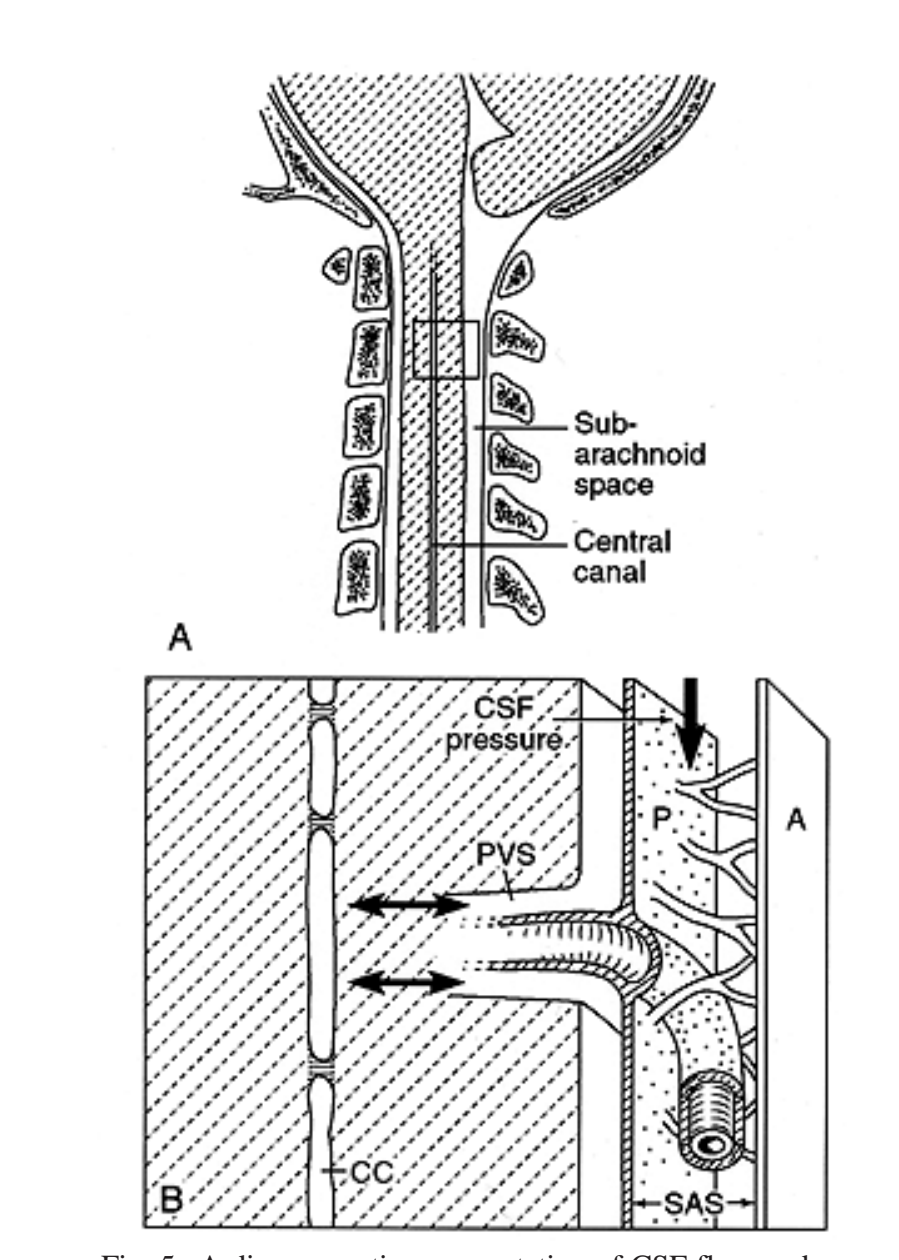

Fig. 5. A diagrammatic representation of CSF flow under normal circumstances. A: Sagittal view of the craniocervical junction and upper cervical spinal cord in an anatomically normal patient shows no obstruction to CSF flow at the foramen magnum. A segment of spinal cord parenchyma (box) is shown in more detail in part $B$. B: Magnified view of the box in part $A$ shows CSF flow dynamics in a normal patient with a variably stenotic central canal (CC), as indicated by the horizontal lines. CSF pressure (vertical arrow) is normal. CSF flows from the subarachnoid space (SAS) between the arachnoid (A) and pia (P) to the subpial space, and then enters the perivascular space (PVS). CSF circulates through the cord parenchyr the cord parenchyma toward the central canal, but may also flow in reverse as these forces are relatively balanced under normal circumstances (double-headed arrows).

arachnoid space below the level of obstruction, imparts an accentuated systolic pressure wave into the upper cervical spinal canal, forcing CSF into spinal cord parenchyma during systole. Oldfield et al. ${ }^{29}$ believed that their hypothesis might explain the origin and progression of noncommunicating syringes associated with the hindbrain malformations as well as with other conditions that obstruct CSF flow in the spinal subarachnoid space, such as arachnoiditis and extramedullary tumors. An alternative hypothesis ${ }^{30}$ suggests that the cause of hydromyelic cavities associated with the Chiari I malformation may not be that fluid is driven into the cervical cord from some external source, but rather that fluid that normally exits the cord cannot escape. However, recent experimental study ${ }^{40}$ indicates that flow is into the central canal from perivascular spaces.
Syringomyelia is commonly observed in the posttrauma setting. ${ }^{1-3}$ In the case of trauma, the inciting event for syrinx formation is focal cord injury, although the propagation of a posttraumatic syrinx may certainly be related at least in part to alterations in CSF flow. ${ }^{30}$ In trauma patients, a condition termed progressive posttraumatic myelomalacic myelopathy (PPMM) has been described that is considered to represent a continuum of interrelated disease processes that may precede formation of a confluent cyst. ${ }^{31}$ Patients with PPMM are generally clinically indistinguishable from those with cystic myelopathy, and, in some cases, have been reported to have a microcystic myelopathy ${ }^{30-35}$ The presence of localized arachnoiditis at the level of trauma leading to spinal cord tethering is considered to play an important role in the pathophysiology of PPMM, related at least in part to changes in local CSF dynamics. $^{30,31}$ Analogous to the situation of PPMM, our patients had myelopathic symptoms associated with conditions that predisposed them to syrinx formation. To our knowledge, this has not been documented in patients without a history of trauma.

Specifically, the underlying conditions in our patients included Chiari I malformation, cervical spondylostenosis, and arachnoiditis, all of which are associated with both impedance to normal CSF flow and syrinx formation. All of our patients presented with nonspecific myelopathic symptoms, similar to patients described by Milhorat et al, ${ }^{23}$ with non-communicating syringomyelia, and demonstrated findings on MR images similar to those seen in cases of progressive posttraumatic myelomalacic myelopathy, ${ }^{7,19}$ including cord enlargement and $T_{1}$ and $T_{2}$ prolongation, with the $\mathrm{T}_{1}$ signal not as low as that of CSF and not sharply marginated. In the distinction between cystic and noncystic myelopathy, proton density-weighted images may be useful, since a cyst would be expected to be isointense with CSF whereas myelomalacic or microcystic changes would likely by hyperintense; ${ }^{42}$ however, proton density-weighted images may not be completely reliable, since a cyst may be hyperintense to CSF on a proton density-weighted images because of dampened CSF pulsations or a slightly elevated protein content. In addition, with the advent of fast spin-echo imaging of the spine, double-echo spin-echo sequences have been dropped from many imaging protocols, and we do not perform it routinely at our institution. Axial $\mathrm{T}_{1}$-weighted images may also be useful in the distinction of cystic from noncystic changes. Intraoperative sonography is certainly a useful adjunct in the assessment of cystic versus noncystic myelopathy, ${ }^{7,11,33,42}$ but the performance of this examination varies among institutions and among individual surgeons and requires operative exposure.

Findings strongly supporting disturbance of CSF flow were observed on preoperative imaging studies in four of our five patients, and the surgical procedures performed were either directed at restoring patency of CSF pathways or had that end effect in all patients. We do not have direct information on the status of the central canal in our patients, but we hypothesize that it was not patent and, thus, CSF that was driven into the spinal cord parenchyma by alterations in normal flow patterns was unable to enter the central canal to form a syrinx (Figs. 5 and 6). After improvement or reconstitution of CSF pathways, all patients demonstrated stabilization or improvement in clinical 
"Presyrinx" state

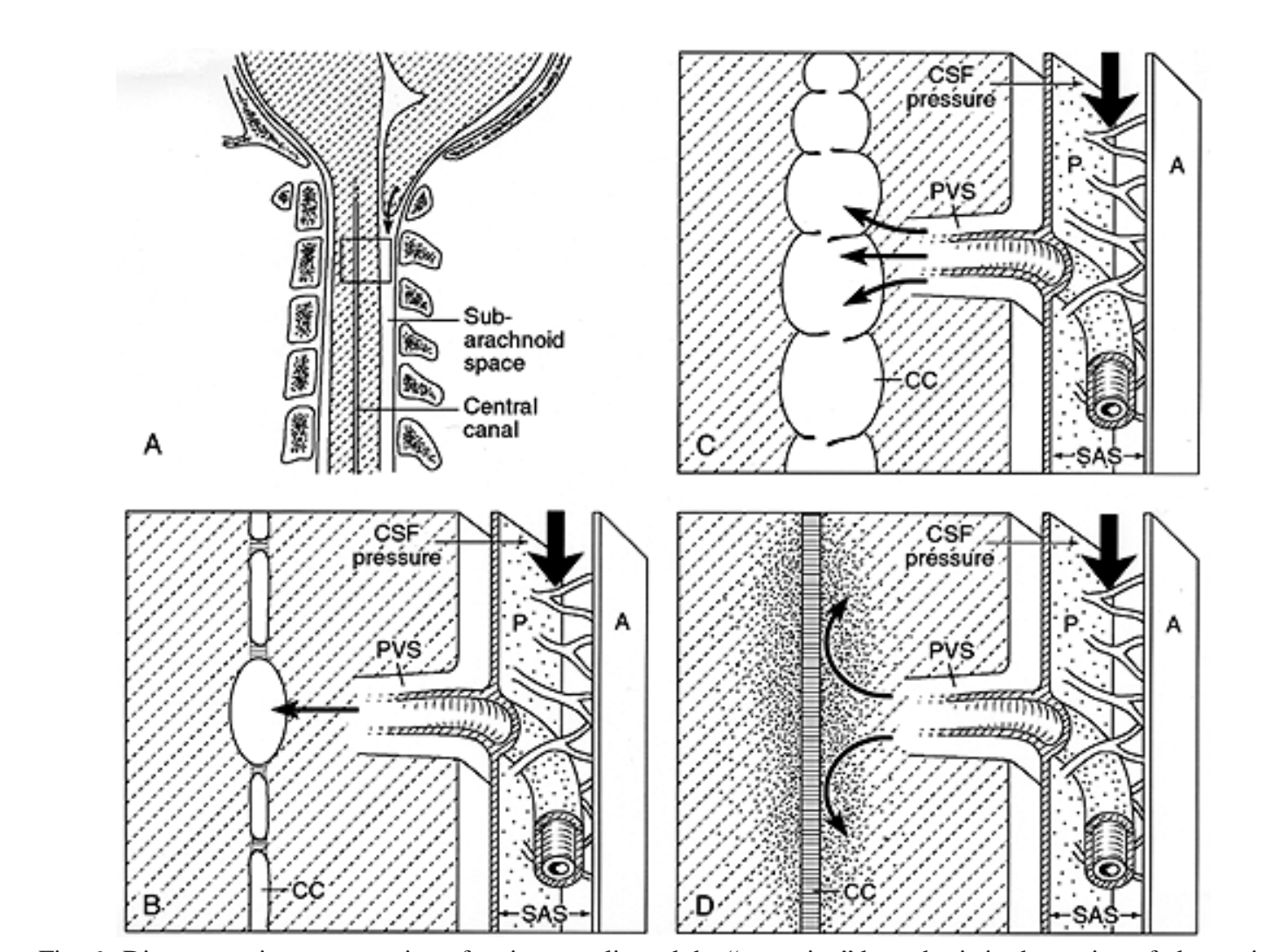

Fig. 6. Diagrammatic representation of syringomyelia and the "presyrinx" hypothesis in the setting of obstruction to CSF flow. A: Sagittal view of the craniocervical junction in a patient with a Chiari I malformation shows abnormal descent of the cerebellar tonsil below the level of the foramen magnum (arrow). A segment of spinal cord parenchyma (box) is magnified in parts $B$ to $D$, which represent views of CSF dynamics at the level of the spinal cord parenchyma in the presence of alterations in normal CSF flow and variable patency of the central canal. B: Focal noncommunicating syrinx. In the setting of a Chiari I malformation and a variably stenotic central canal (which is a normal variant in many adults), as the tonsils descend rapidly during systole, CSF is driven into the spinal cord parenchyma by increased CSF pressure (thick vertical arrow). Net CSF flow occurs toward the central canal, resulting in focal syringomyelia which is SAS = im its craniocaudal extent by intervening stenosis of the central canal. $C C=$ central canal, $A=$ arachnoid, $\mathrm{P}=$ pia, SAS = subarachnoid space, PVS = perivascular space. C: Extensive noncommunicating syrinx. This situation is similar to $\mathrm{B}$, but the central canal is more extensively patent. In this situation, a long-segment dilation of the central canal (curved arrows) occurs as CSF is driven into the central canal via the perivascular spaces by the accentuated CSF pulse pressure (thick vertical arrow) that results from downward motion of the low-lying cerebellar tonsils in systole. D: "Presyrinx". In the setting of altered CSF flow, as with a Chiari I malformation, fluid in the subarachnoid space is subjected to increased pressure (thick vertical arrow). Net CSF flow is into the spinal cord parenchyma; however, because the central canal is not patent (as indicated by the horizontal lines), fluid cannot accumulate within the central canal (curved arrows) and therefore diffuses through the cord parenchyma (stippled area), resulting in cord enlargement and edema.

symptoms. Additionally, postoperative MR examinations showed both a reduction in cor ment in cord parenchymal signal abnormalities. Whether the signal alterations represent edema or microcystic change or both is unclear, since pathologic specimens are not available from these patients. A direct traumatic injury to the cord does not appear to be a necessary prerequisite for the development of this condition. A difficulty with this hypothesis is explaining the later development of frank cavitation in Case 3, however, it is possible that partial recanalization of the central canal may have occurred, followed by paracentral dissection around a stenotic segment. ${ }^{25}$ Alternatively, the myelotomy performed during the initial surgery may have created a pathway along which a syrinx could form and then extend.

Jinkins, et al., ${ }^{15}$ recently described three patients with clinically progressive posttraumatic syringomyelia in whom extensive MR signal change on $\mathrm{T}_{2}$-weighted images in the spinal cord superior to a well-defined syrinx was found to be an ancillary sign of disease progression. After shunting of the syrinx, the parenchymal $\mathrm{T}_{2}$ hyperintensity resolved, and neurological deficits stabilized or improved. They postulated that the $\mathrm{T}_{2}$ hyperintensity represented fluid escaping from the cyst or edema caused by as yet undefined pathologic alterations in the spinal cord adjacent to the cyst. In these cases, a definite obstruction to flow of CSF was not described, and the intervention taken (syrinx shunting) was not aimed at restoring patency of CSF pathways. It is possible that the enlarged cord caused relative obstruction of normal CSF flow pathways, resulting in a "presyrinx" condition cranial to the already formed syrinx cavity. In a case that presented following our initial report, ${ }^{8}$ we observed extensive MR signal change superior to a frank syrinx in a patient with exten- 
N. J. Fischbein, et al.

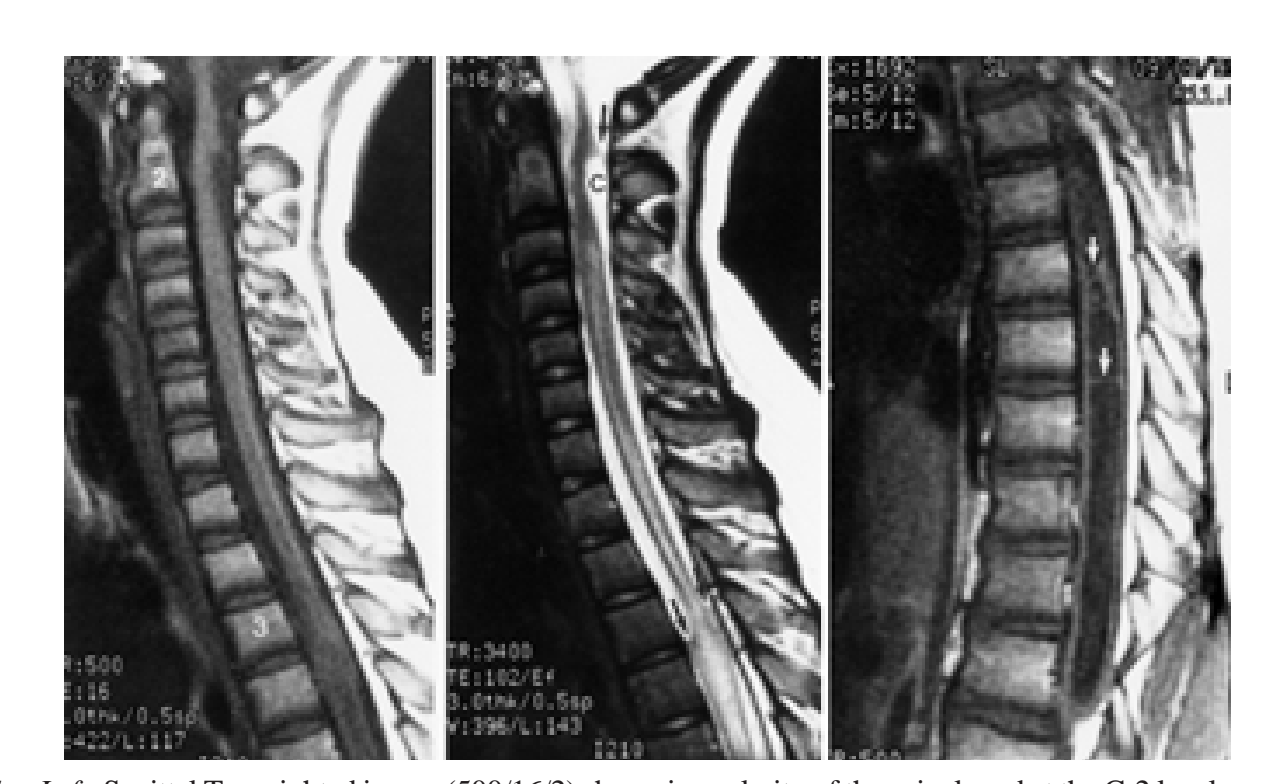

Fig. 7. Left: Sagittal $\mathrm{T}_{\text {- }}$-weighted image (500/16/2) shows irregularity of the spinal cord at the C-2 level, and a change in caliber of the cord at the T3-4 level. The cord appears mildly hypointense below T3-4, and there is no evidence of frank cavitation. Center: Sagittal fast-spin echo $\mathrm{T}_{2}$-weighted image (3400/102 Eff/2) shows adhesions at the C-2 and T3-4 levels (arrows), with a secondary arachoid cyst (right) dorsal to the cord at the C-2 level. The cord shows increased $\mathrm{T}_{2}$ signal from C-3 caudad. These "presyrinx" changes are presumably due to alterations in CSF flow caused by the postinflammatory adhesions. Right: More inferiorly, a sagittal $\mathrm{T}_{1}$-weighted image (500/16/2) through the thoracic spinal cord shows evidence of frank syrinx formation, with clear-cut cavitation and internal septations (arrows).

sive arachnoid adhesions due to neonatal meningitis (Fig. 7) who presented with gradually progressive myelopathy, supporting the idea of a continuum between the "presyrinx" state and syringomyelia and showing that trauma is not a necessary precondition for the appearance described by Jinkins, et al. ${ }^{15}$

In further support of our hypothesis, the reversibility of cord signal abnormality associated with obstruction to normal CSF flow has been demonstrated in a case of acquired tonsillar herniation caused by probable spontaneous intracranial hypotension. ${ }^{20,28,38}$ In this case, the cervical cord was enlarged and demonstrated $\mathrm{T}_{1}$ and $\mathrm{T}_{2}$ prolongation without frank cavitation, consistent with the "presyrinx" state. After spontaneous resolution of the patient's condition (presumably because of closure of an occult CSF leak), the cerebellar tonsils returned to a normal position, and the cervical cord caliber and signal reverted to normal. The patient was not myelopathic but did experience occipital and neck pain. The lack of myelopathic symptoms is not inconsistent with presyrinx physiology, since even patients with frank syringomyelia (typically of the central cavitary type) may be asymptomatic. ${ }^{2 .}$ Because surgical intervention was performed that restored or improved CSF flow pathways in all our patients, we are unable to prove that they would have progressed to frank syrinx formation. The implication that syrinx formation would have occurred if the patients were left untreated is justified by the following three considerations: first, the underlying conditions in our patients all have a known association with syringomyelia; second, in one patient (Case 3) who initially responded to surgical intervention with marked improvement in cord enlargement and signal abnormality, clear-cut syrinx formation occurred during the follow-up period, presumably because the underlying obstruction to CSF flow had not been fully addressed by the surgical procedure performed; and third, the recent observations of Jinkins, et al., ${ }^{15}$ which suggest reversible $\mathrm{T}_{2}$ changes were considered to predict frank syrinx formation. We therefore propose the use of the term

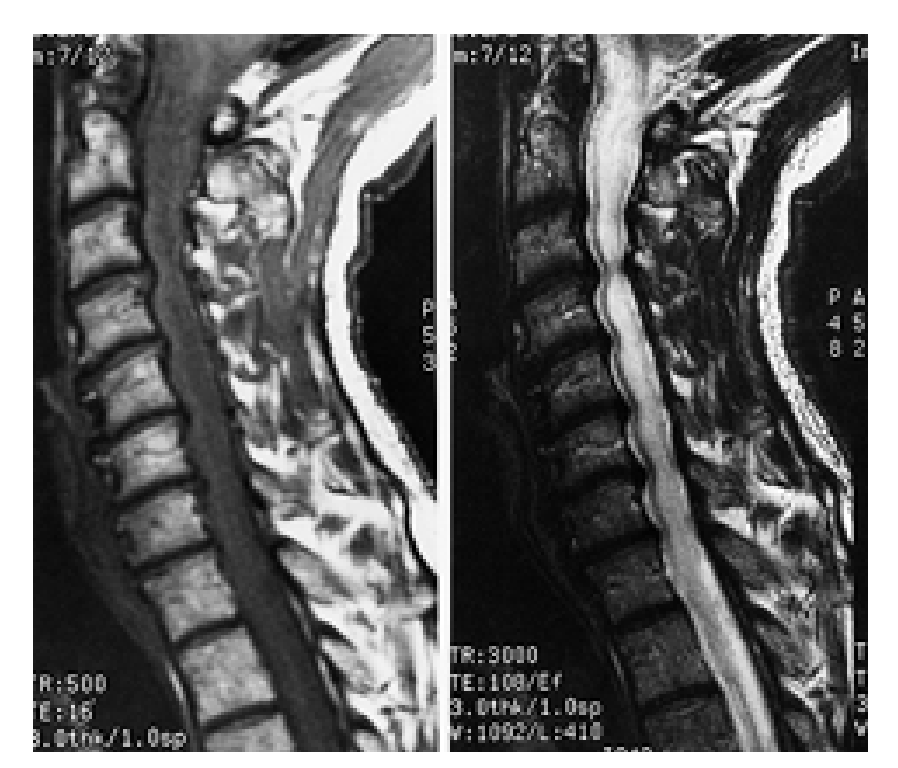

Fig. 8. Left: Sagittal $\mathrm{T}_{1}$-weighted image (500/16/2) shows an abnormally enlarged and hypointense cervical spinal cord. The defined, suggesting that there may be abnormal soft tissue consisthe Right: A sagittal (3000/108 Eff/3) Shows a sittal fast-spin echo $\mathrm{T}_{2}$-weighted image (3000/108 Eff/3) shows abnormal hyperintensity throughout the cervical spinal cord. The enlargement and signal characteristics are consistent with an edematous cord. There is no frank cavitation, and no focal enhancement was present after gadolinium injection (not shown). 


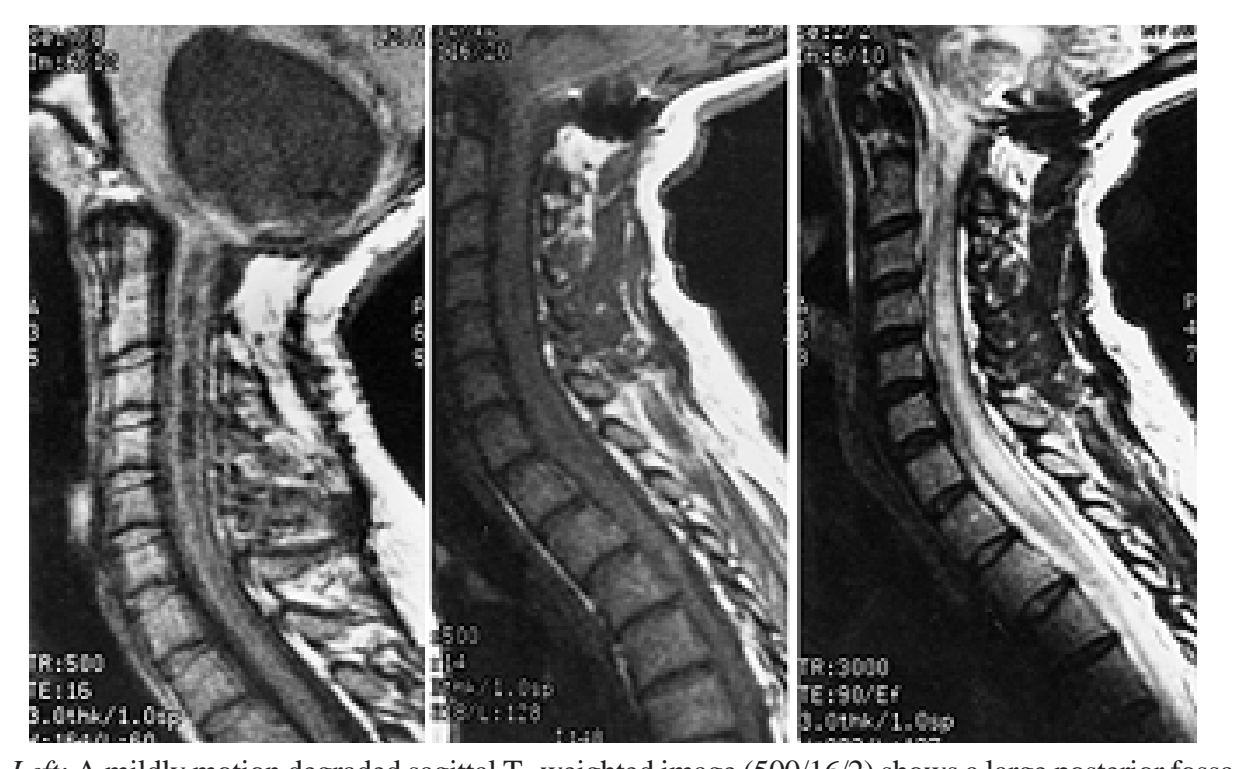

Fig. 9. Left: A mildly motion degraded sagittal $\mathrm{T}_{1}$-weighted image (500/16/2) shows a large posterior fossa cyst causing mass effect on the brainstem and obstruction at the foramen magnum. Central cavitation is present in the upper cervical cord, consistent with syringomyelia. Center: Following cyst decompression, a sagittal $\mathrm{T}_{1}$-weighted image (500/14/2) shows resolution of the frank cavitation, although the upper cervical cord remains mildly enlarged and hypointense. Right: A fastspin echo $\mathrm{T}_{2}$-weighted image (3000/90/3) confirms abnormal $\mathrm{T}_{2}$ hyperintensity throughout the cervical spinal cord.

"presyrinx" state as a valid concept to describe these and similar cases.

Since the report of these initial five patients, ${ }^{8}$ we have identified three additional patients who we think illustrate important features of the "presyrinx" spectrum and provide further support for consideration of this entity. One is described above and is shown in Fig. 7. A second patient with a history of remote surgery for a brain tumor developed a progressive myelopathy and appeared to have basal arachnoiditis and edema of the cervical spinal cord on MR (Fig. 8). His symptoms improved following foramen magnum decompression and lysis of adhesions, but a follow-up MR has not been obtained. Finally, we have identified an interesting patient with a history of parenchymal hemorrhage due to a cerebellar arteriovenous malformation and subsequent development of a posterior fossa cyst who was treated with cyst-peritoneal shunting. When the shunt obstructed, the cyst enlarged, the patien became progressively myelopathic, and imaging demonstrated a frank cervical syrinx. When the shunt was revised and the cyst decompressed, the patient developed low pressure headaches and evidence of intracranial hypotension $^{9,34}$ but her macrocysts regressed and her cord developed a "presyrinx" appearance (Fig. 9). Subsequent scans revealed fluctuation between a frankly cavitary lesion and an enlarged, edematous-appearing cord depending on the size of the cyst and functional status of the cyst-peritoneal shunt. We feel this case is important in demonstrating the delicate dynamic that may exist between a pre-cavitary and a frankly cavitary state. This case is also problematic, however, in that it also demonstrates the role of central canal patency is probably quite complex and may not always be the dominant mechanism for entry into a "presyrinx" state. Unlike patient 3, whose progression to frank syrinx may have been influenced by a prior myelotomy, this patient had no history of spinal cord surgery.

We have also considered other possible causes of the reversible cord enlargement and $\mathrm{T}_{2}$ prolongation identified in our patients. It seems unlikely that arterial ischemia plays a significant role in the pathogenesis of the presyrinx state based on the fact that the imaging abnormalities did not conform to a vascular territory and were reversible as assessed by postoperative imaging. Venous ischemia could have played a role in cord enlargement and signal changes, analogous to the pathophysiology of spinal dural arteriovenous fistula, but no abnormal veins were identified at preoperative imaging or intraoperatively. The lack of identification of macroscopic abnormal veins does not, however, exclude a role for venous ischemia. In the setting of trauma, occluded intramedullary veins have been identified in degenerated segments of cord. ${ }^{43}$ In the nontraumatic setting, it is possible that pressure changes in the epidural venous plexus in association with disturbances of CSF circulation lead to an increase in spinal venous pressure and accumulation of fluid in the spinal cord. ${ }^{18}$ Venous ischemic changes are also known to be reversible. However the venous drainage of the spinal cord is quite rich, and the mechanism by which venous ischemia would have occurred in our patients is not clear. Therefore, although we propose that the "presyrinx" state is fundamentally one of altered CSF flow parameters, we do recognize that a contribution of venous ischemia may be present as well and that sorting out these relationships will require further study.

The relationship between the level of the block to CSF flow and the location of the presyrinx lesion also warrants consideration. As most of our cases had high cervical or foramen magnum blockages to CSF flow, it is not surprising that the spinal cord parenchymal signal changes that 
we observed developed caudal to the block. Pathophysiologically, this is most likely related to fluid entering the cord below the level of the block and then tracking cephalad in cord parenchyma and/or the central canal to circumvent the block; however, in the experience of Jinkins, et al., ${ }^{15}$ which we consider an analogous situation, the presyrinx lesion extended rostral to the level of obstruction In the setting of trauma, syringes most commonly extend superiorly from the site of injury, although superior and inferior extension, and even inferior extension alone, have been observed. This may relate to the fact that the cervical cord expands more easily than the thoracic cord. ${ }^{17,32,45}$

An important but as yet unexplained aspect of this phenomenon is why we do not see these MR findings more frequently in cases of Chiari I malformations and basal arachnoiditis, as these are not uncommon conditions. Because patients in the presyrinx state may have minima clinical symptoms or even be asymptomatic, they may not come to medical attention until frank cavitation and more severe symptoms have developed. Additionally, a dynamic balance between CSF pressure in the spinal subarachnoid space and the spinal cord parenchyma may exist, and the anatomic conditions required to establish the presyrinx state may occur only rarely. For instance, the establishment of this state may depend on the morphology and extent of the network of spinal perivascular spaces and the capacity and patency of the central canal, among other factors. Intervention at an appropriate time may allow restoration of normal flow patterns and reversal of parenchymal signal abnormalities, as well as improvement in neurological deficits. That this entity may represent an equilibrium state is supported by the documentation of this appearance in one of our patients (Case 2) for some time before she progressed symptomatically to the poin that surgical intervention was performed. Further study will be necessary to better understand normal and abnormal spinal subarachnoid fluid circulation and the pathophysiology of syrinx formation.

\section{CONCLUSION}

We have described a condition of reversible spinal cord enlargement and $\mathrm{T}_{1}$ and $\mathrm{T}_{2}$ prolongation, the "presyrinx" state, which occurs in the setting of CSF flow obstruction and may be misinterpreted as syringomyelia on MR studies. Surgical intervention aimed at restoring patency of CSF pathways is likely to be of benefit in these patients, and MR findings should guide selection of the procedure to be performed. This entity presumably represents a point on the continuum to development of syringomyelia and may be pathophysiologically related to variations in the patency of the central canal and also to the entity of progressive posttraumatic myelomalacic myelopathy.

\section{References}

1. Aubin ML, Baleriaux D, Cosnard G, et al: MRI in syringomyelia of congenital, infectious, traumatic or idiopathic origin. A study of 142 cases. J Neuroradiol 14:313-336, 1987

2. Ball MJ, Dayan AD: Pathogenesis of syringomyelia. Lancet 2:799-801, 1972

3. Brammah TB, Jayson MIV: Syringomyelia as a complication of spinal arachnoiditis. Spine 19:2603-2605, 1994
4. Caplan LR, Norohna AB, Amico LL: Syringomyelia and arachnoiditis. J Neurol Neurosurg Psychiatry 53:106-113, 1990

5. Cho KH, Iwasaki Y, Imamura H, et al: Experimental model of postraumatic syringomyelia: the role of adhesive arachnoiditis in syrinx formation. J Neurosurg 80:133-139, 1994

6. Cifuentes M, Fernandez-Llebrez P, Perez J, et al: Distribution of intraventricularly injected horseradish peroxidase in cerebrospinal fluid compartments of the rat spinal cord. Cell Tissue Res 270:485-494, 1992

7. Falcone S, Quencer RM, Green B, et al: Progressive posttraumatic myelomalacic myelopathy: imaging and clinical features. AJNR 15:747-754, 1994

8. Fischbein NJ, Dillon WP, Cobbs C, et al: The "presyrinx" state: a reversible myelopathic condition that may precede syringomyelia. AJNR 20:7-20, 1999

9. Fishman RA, Dillon WP: Dural enhancement and cerebral displacement secondary to intracranial hypotension. Neurology 43:609-611, 1993

10. Gardner WJ: Hydrodynamic mechanism of syringomyelia: its relationship to myelocele. J Neurol Neurosurg Psychiatry 28: $247-259,1965$

11. Gebarski SS, Maynard FW, Gabrielsen TO, et al: Posttraumatic progressive myelopathy. Radiology 157:379-385, 1985

12. Heiss JD, Patronas N, DeVroom HL, et al: Elucidating the pathophysiology of syringomyelia. J Neurosurg 91: 553-562, 1999

13. Houang MT, Stern M, Brew B, et al: Magnetic resonance imaging (MRI) appearances of syringohydromyelia. Australas Radiol 32:172-177, 1988

14. Hutchings M, Weller RO: Anatomical relationships of the pia mater to cerebral blood vessels in man. J Neurosurg 65: 316-325, 1986

15. Jinkins JR, Reddy S, Leite CC, et al: MR of parenchymal spinal cord signal change as a sign of active advancement in clinically progressive posttraumatic syringomyelia. AJNR 19: 177-182, 1998

16. Kaar GF, N'Dow JM, Bashir SH: Cervical spondylotic myelopathy with syringomyelia. Br J Neurosurg 10:413-415, 1996

17. Klekamp J, Batzdorf U, Samii M, et al: Treatment of syringomyelia associated with arachnoid scarring caused by arachnoiditis or trauma. J Neurosurg 86:233-240, 1997

18. Klekamp J, Samii M, Tatagiba M, et al: Syringomyelia in association with tumors of the posterior fossa: pathophysiological considerations, based on observations on three related cases. Acta Neurochir 137:38-43, 1995

19. Lee TT, Arias JM, Andrus HL, Quencer RM, et al: Progressive posttraumatic myelomalacic myelopathy: treatment with untethering and expansive duraplasty. J Neurosurg 86:624-628, 1997

20. Mamelak AN, Fishman RA, Dillon WP, et al: Spontaneous intracranial hypotension. J Neurosurg 1996, 85:192-193, 1996 (Letter)

21. Milhorat TH, Adler DE, Heger IM, et al: Histopathology of experimental hematomyelia. J Neurosurg 75:911-915, 1991

22. Milhorat TH, Capocelli AL Jr, Anzil A, et al: Pathological basis of spinal cord cavitation in syringomyelia: analysis of 105 autopsy cases. J Neurosurg 82:802-812, 1995

23. Milhorat TH, Johnson RW, Milhorat RH, et al: Clinicopathological correlations in syringomyelia using axial magnetic resonance imaging. Neurosurgery 37:206-213, 1995

24. Milhorat TH, Johnson WD, Miller JI, et al: Surgical treatment of syringomyelia based on magnetic resonance imaging criteria. Neurosurgery 31:231-245, 1992

25. Milhorat TH, Kotzen RM, Anzil AP: Stenosis of central canal of spinal cord in man: incidence and pathological findings in 232 autopsy cases. J Neurosurg 80:716-722, 1994

26. Milhorat TH, Miller JI, Johnson WD, et al: Anatomical basis of syringomyelia occurring with hindbrain lesions. Neurosurgery 32:748-754, 1993

Neurosurg. Focus / Volume 8 / March, 2000 
27. Milhorat TH, Nobandegani F, Miller JI, et al: Noncommunicating syringomyelia following occlusion of central canal in cating syringomyelia following occlusio

28. Morioka T, Shono T, Nishio S, et al: Acquired Chiari I malformation and syringomyelia associated with bilateral chronic subdural hematoma. Case report. J Neurosurg 83:556-558, 1995

29. Oldfield EH, Muraszko K, Shawker TH, et al: Pathophysiology of syringomyelia associated with Chiari I malformation of the cerebellar tonsils. Implications for diagnosis and treatment. J Neurosurg 80:3-15, 1994

30. Olivero WC, Dinh DH: Chiari I malformation with traumatic syringomyelia and spontaneous resolution: case report and literature review. Neurosurgery 30:758-760, 1992

31. Phanthumchinda K, Kaoropthum S: Syringomyelia associated with post-meningitis spinal arachnoiditis due to Candida tropicalis. Postgrad Med 67:767-769, 1991

32. Quencer RM, Green BA, Eismont FJ: Posttraumatic spinal cord cysts: clinical features and characterization with metrizamide computed tomography. Radiology 146:415-23, 1983

33. Quencer RM, Morse BMM, Green BA, et al: Intraoperative spinal sonography: adjunct to metrizamide CT in the assessment and surgical decompression of posttraumatic spinal cord cysts. AJR 142:593-601, 1984

34. Rando TA, Fishman RA: Spontaneous intracranial hypotension: report of two cases and review of the literature. Neurology 42 481-487, 1992

35. Rennels ML, Blaumanis OR, Grady PA: Rapid solute transport throughout the brain via paravascular fluid pathways. Adv Neurol 52:431-439, 1990

36. Rennels ML, Gregory TF, Blaumanis OR, et al: Evidence for 'paravascular' fluid circulation in the mammalian central nervous system, provided by the rapid distribution of tracer protein throughout the brain from the subarachnoid space. Brain Res 326:47-63, 1985

37. Rossier AB, Foo D, Shillito J, et al: Posttraumatic cervical syringomyelia. Brain 108:439-461, 1985

38. Schievink WI, Atkinson JLD: Spontaneous intracranial hypotension. J Neurosurg 1996, 84:151-152, 1996 (Letter)
39. Stoodley MA, Brown SA, Brown CJ, et al: Arterial pulsationdependent perivascular cerebrospinal fluid flow into the central canal in the sheep spinal cord. J Neurosurg 86:686-693, 1997

40. Stoodley MA, Gutschmidt B, Jones NR: Cerebrospinal fluid flow in an animal model of noncommunicating syringomyelia. Neurosurgery 44:1065-1076, 1999

41. Stoodley MA, Jones NR, Brown CJ: Evidence for rapid fluid flow from the subarachnoid space into the spinal cord central canal in the rat. Brain Res 707:155-164, 1996

42. Tanghe HLJ: Magnetic resonance imaging (MRI) in syringomyelia. Acta Neurochir 114:93-99, 1995

43. Tator CH, Koyanagi I: Vascular mechanisms in the pathophysiology of human spinal cord injury. J Neurosurg 86:483-492, 1997

44. Vernon JD, Silver JR, Ohry A: Posttraumatic syringomyelia. Paraplegia 20:339-364, 1982

45. Watson N: Ascending cystic degeneration of the cord after spinal cord injury. Paraplegia 19:89-95, 1981

46. Williams B: The distending force in the production of "communicating syringomyelia.” Lancet 2:189-193, 1969

47. Williams B, Bentley J: Experimental communicating syringomyelia in dogs after cisternal kaolin injection. Part I. Morphology. J Neurol Sci 48:93-107, 1980

48. Zhang ET, Inman CBE, Weller RO: Interrelationships of the pia mater and the perivascular (Virchow-Robin) spaces in the human cerebrum. J Anat 170:111-123, 1990

Manuscript received November 15, 1999.

Accepted in final form December 24, 1999.

An earlier version of this manuscript was published in the American Journal of Neuroradiology, Am J Neuroradiol 20:7-20, 1999.

Address reprint requests to: Nancy J. Fischbein, M.D., Department of Radiology, Box 0628, University of California, San Francisco, 505 Parnassus Avenue, San Francisco, California 94143 0628. email: Nancy.Fischbein@ radiology.ucsf.edu. 